\title{
Problems in English to Arabic Subtitles Translation of Religious Terms - Bruce Almighty and Supernatural on MBC \& Dubai One: A Case Study
}

\author{
Ahmed Abdel Azim ElShiekh ${ }^{1}$ \\ ${ }^{1}$ Alexandria University, Chatby, Alexandria, Egypt \\ Correspondence: Ahmed Abdel Azim ElShiekh, Associate Professor emeritus, English department, Faculty of \\ Arts, Alexandria University, Chatby, Alexandria, Egypt. E-mail: shishuj@gmail.com
}

Received: November 14, 2015 Accepted: December 2, 2015 Online Published: January 31, 2016

doi:10.5539/ijel.v6n1p38 URL: http://dx.doi.org/10.5539/ijel.v6n1p38

\begin{abstract}
This paper attempts to shed light on some cultural and/or technical problems in the translation of religious terms from English into Arabic in the subtitles of movies, with particular reference to some Arab Gulf countries channels. Due to limitations of time and space, the researcher has taken two particular channels as representative, namely MBC Channel group and Dubai One. The data of the research have been collected from one film and one TV series as quite typical examples of works that may lead to serious problems in the subtitles translation with regard to religious terms. In both cases, the use of religious terms is not only obligatory but also focal. The researcher points the discrepancies in the choice of Arabic equivalents for the English religious terms in question as well as explores the possible reasons of and recommended solutions to such cultural problems in translation. The film, Bruce Almighty, is a light and comic treatment of the phenomenon of well-educated yet vain young men, doubting the wisdom of God Almighty. Jim Cary plays the role of the young man, while Morgan Freeman actually plays God! Hence, there is no easy way out of the necessity of tackling the problem of translating the religious terms involved. As for the TV series, Supernatural, the whole episode deals with God, angels, demons and Satan. It remains to be said that this paper does not claim to give decisive answers to the questions posed by the research, but only aspires to pave the way before further research on the topic and related issues.
\end{abstract}

Keywords: religious terms, subtitles, Gulf channels, God, Satan, angels, demons, cultural problems, translation

\section{Introduction}

This paper attempts to shed some light on cultural problems reflected in the translation of religious terms in the subtitles of movies from English into Arabic with particular reference to some Arab Gulf countries channels.

\subsection{Objectives of the Research}

This researcher aims at studying some cultural problems in the Arabic subtitles translation of some religious terms as well as exploring the possible reasons for these problems with particular reference to some Arab Gulf TV channels. In other words, this research aspires to identify whether the causes of such problems are mainly technical or should be, basically, attributed to particular cultural attitudes.

\subsection{Scope of the Research}

Due to limitations of time and space, however, the researcher has taken two particular channels as representative of Gulf channels, namely MBC Channel group and Dubai One.

\subsection{Data Collection}

The data of the research have been collected from one film and one TV series as quite typical examples of works that may lead to serious problems in the subtitles translation with reference to religious terms.

\section{Relevant Background}

This part of the research shall attempt to give a brief review of what the researcher believes to relevant 
background to the particular topic and objectives of this paper.

\subsection{Subtitle Translation}

To quote David Orrego-Carmona, "The globalization of audiovisual content and the configuration of international media flows have had a major impact on the expansion of non-professional subtitling and, at the same time, on users' general view of subtitling" (David Orrego-Carmona, 2014).

Yet, in the two cases under study in this paper, the two translators responsible for the subtitles in question are not supposed to be amateurs or volunteers in any way. This is a case of a professional, hence paid, translation of subtitles.

In both cases, the use of religious terms is not only obligatory but also focal. The researcher points the discrepancies in the choice of Arabic equivalents for the English religious terms in question as well as explores the possible reasons and recommended solutions to such cultural problems in translation.

The film, Bruce Almighty, is a light and comic treatment of the phenomenon of educated young men doubting the wisdom of God Almighty. Jim Cary plays the role of the young man while Morgan Freeman actually plays God!

As for the TV series, Supernatural, the whole episode deals with God, angels, prophets, demons and the Devil or Lucifer. Hence, there is no easy way out of the necessity of tackling the problem of translating the religious terms involved.

\section{Bruce Almighty}

Bruce Nolan, a television reporter in Buffalo, N. Y., is discontented with almost everything in life despite his popularity and the love of his girlfriend Grace. At the end of the worst day of his life, Bruce angrily ridicules the power of fate, which he hardly believes in, and rages against God. Therefore, God responds.

God appears in human form and, endowing Bruce with divine powers, challenges him to take on the big job to see if he can do it any better.

\section{Supernatural}

Two brothers follow their father's footsteps as "hunters" fighting evil supernatural beings of many kinds including monsters, demons, and gods that roam the earth.

\section{Findings \& Discussion}

This section of the research attempts to shed light on the most important findings of the research as well as shed light on their significance and the possible reasons that, may have led to them.

\subsection{Findings}

The major findings relevant to the present research shall be surveyed in the following section.

\subsubsection{First, with Regard to Bruce Almighty}

a) The lexeme God is used 29 times

b) Bruce $=15$

c) God $=7$ times

d) $\quad$ Grace $=9$ times

e) Other minor characters $=7$ times

It is worth noting in this respect that the lexical item 'God' occurs twice in idiomatic expressions such as "Oh God" and "Oh my God". In these two instances in particular the lexeme 'God' was translated into the Arabic regardless of who the speaker may be. In all other instances, the term God is consistently translated into the Arabic القير

The very same translations happen to be almost the exact ones used in MBC 2 as well, with one obvious exception. The term 'God' is consistently translated into the Arabic القدر. Other differences are confined to "My Lord" which is translated into يا إلهي.

\subsubsection{Second, with Regard to Supernatural}

a) The lexeme God is used 7 times, 6 of which are rendered into القدير on the Dubai One and 7 times into on the MBC, but only once into قدرات خارقة rendered into عندما أردت أن تكتسب قدرات خارقة on the Dubai One. 
b) On the other hand, the lexeme 'Devil' occurs twice, both of which are rendered into الثريز on both channels.

c) The lexeme Demon in the singular and plural is rendered into عفاريت and on the Dubai One in the episode under study, but in another much earlier season (Season 1), they were translated into شرير -أشرار , which are also the translations used by MBC in the subtitles of this very episode. The terms occur 13 times by the different characters.

d) The terms 'Angel' and 'Angels' occur 17 times in the episode under examination and are all rendered on the Dubai One in this episode as ملاك ـملائكة even though they were translated into الخير والأخيار in in in and are still translated in the same way in MBC.

e) The term 'Lucifer' occurs twice and is simply transliterated into Arabic as لوسيفر. As for the term 'heavens', it occurs twice too and is referred to in Arabic as أرض النعيم

f) The term Saint is used only once with reference to a feminine character and is rendered in the Arabic subtitles as التقية

g) Finally, the lexeme Prophet occurs 7 times, all of which refer to an inferior character in the episode. In other words, the term is not used to refer to any known Biblical or Koranic prophet. Furthermore, that so-called prophet is chosen by the demons, not God!

Unlike the case with terms such as God, the Devil, demons and angels, where the subtitle translation avoids the use of terms with strong religious connotations, the term 'Prophet' is translated into an Arabic religious term that is more or less a natural equivalent per se of the English 'messenger'. It is translated into رسو rather than نبي

However, the English 'gods' in the phrase 'No more prophets or new gods' is translated into الآلهة الجد in both channels, equally.

\subsection{Discussion}

The following section attempts to explore the possible reasons underlying the phenomenon in question. The researcher endeavours to do so through presenting each possible reason in turn, examining its probability or even possibility, excluding the highly improbable ones. Eventually, this technique should probably lead to the identification of the most likely reason or reasons.

3.2.1 Possible Reasons for the Problems in Question: Mainly Technical or Attributed to Particular Cultural Attitudes

The question now arises: Who is the translator in each case? Could it be the same translator, translation office or agency that was responsible for the translation of both works, i.e. the movie and the drama series in both channels, Dubai One and MBC?

The similar, if not even identical, translations are quite evident indicators. Yet, what are we formally told?

In the case of the movie Bruce Almighty, the translation is rendered by a translation office located in Amman, Jordan according to Dubai One and by a translation office located in Cairo, Egypt, according to MBC. Therefore, we clearly have two different translators, not one.

However, what about the drama series Supernatural? The case is stranger still! We are not given any names or any reference to the translator or translators at all. It looks as if the text or script had been automatically translated!

Are we facing a case of an MT rendering of the TV series script? If this is the case, then, how come God is translated differently from "gods" or even "God" in idiomatic expressions?

Automatic machine translation software would keep to the same TL lexical equivalent, automatically. Differences cannot be fairly attributed to lexical options available in a bilingual dictionary or database. It must be due to human preferences. In addition, if such preferences had been basically due to individual decisions taken by individual translators, there would have been some differences in the way the religious terms under study are dealt with in the two works in question as shown on two different channels.

A possible if not even a probable reason for such similar and most often actually identical translations of English religious terms into Arabic would be the presence of a common policy in both channels, according to which, any translator/s of subtitles may be firmly directed to avoid using certain Arabic religious terms, no matter what. 
Another evidence to support that all this is no translator or translators' free choice is that even in other movies and TV series on the two channels in question one may often encounter similar mistranslations for religious terms. A case in point is the terms Jew and Synagogue which are translated into مكان عبادة المتدينين as and المندين as if it were forbidden to refer to Judaism or Jews at all or maybe the only religious people under the sun are only Jews, neither Muslims, Christians nor any followers of any other faith!

Thus, in the light of the aforementioned findings, which approach to translation is adopted, if any? Is it natural equivalence? The answer is clearly in the negative. The so called natural equivalent to God would be and

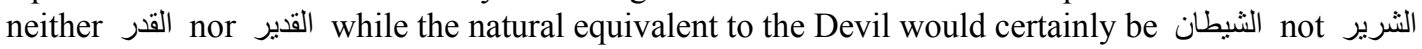

Is it directional equivalence? Is that a case of Friday the 13th and the Spanish Tuesday 13 (Martes 13)? It is true that some Muslim Arabs, especially with Salafi trends, insist on the transliteration of ant into English, on the assumption that the Muslim deity is different from the Christian or Jewish one.

But the start language/culture in our case is English and there could hardly be any dispute that God would simply turn into ال山 in Arabic. This is the very term used by Arab Christians, Arab Jews and even Arab atheists! Unless our ISIL fundamentalists claim God as their sole and exclusive property! It is the term used in the Old Testament, the Book of Genesis and the very term used in the New Testament, in John's Gospel for instance. This is valid regardless of whether we follow the natural or directional equivalence approach. It is valid even if we seek localization or adopt a cultural translation strategy.

What then? Is it Skopos, Re-writing, or is it simply a case of omission and outrageous transformation, or rather more precisely distortion, of the original?

Uncertainty here may seem to be the key term! However, may be the case is still simpler. Maybe there are certain cultural or religious taboos in the translation of certain terms into Arabic, dictated by the management of these two gulf channels.

If this is really the case, the question is not only how far are we entitled to 'transform' a start text from an ethical point of view, but also, on a practical level, why should we have to do so at all? The two works under study are clearly based on religious concepts, deal with religious issues, and do so in highly untraditional ways. So, if all such religious issues are downright taboos in the countries that own the two channels in question, then why bother show the two problematic works at all? Or, alternatively, why not show them with no subtitles whatsoever? Dubai One, for instance, does so with a drama series called Brazil Avenue.

This is not simply a case of avoiding a faithful translation of all swearing terms as in almost all Arab TV Channels and cinemas all four lettered words are miraculously translated into either اللعنة - الو غد or the like. In other words, we are not simply dispensing with some cultural bound terms for the sake of addressing a certain local audience with a different cultural background. We are, in fact, destroying the whole work. In fact, this may recall to memory a translation made by Lutfeyya Al Delimy of The Diary of Anaïs Nin, where the translator explicitly states in her preface that she has refrained from translation many bits and pieces from the start text so as not to offend the Arab reader! She, then, advises the reader to read the original if really interested! As if you invite someone to have lunch but then tell him/her that you have introduced major changes that would render the dish unrecognizable! Finally, you advise your guest to go the closest restaurant available in case they were keen on known how the original dish tastes like!

Nevertheless, at least, the translator has already drawn the addressees' attention to the distortion that has undergone the original work, too much to be said of Dubai One and MBC!

\section{An After Shot!}

In brief, we are not dealing with a translation approach or strategy problem here as much as with a problematic cultural attitude. The question should not really have to be which translation strategy to follow, but do we really have the right to mess up with the minds of our audience so as to protect them against the vices of the west? Are we the guardians of our peoples? How much different is this from the ingenious ideas and attitudes of the criminals and assassins of ISIL?

No one has access to the abstract truth; no one has the right to impose his/her ideas and attitudes on others. If translation is truly a bridge, then let it actually bridge the gap between different cultures, between different ages and seek the essence of the one and same human civilization.

The human civilization as we have it now is neither an exclusively western product, nor a purely oriental one. It is simply the accumulation of the contributions of different cultures, different thinkers, different religions and different human beings. And, along that process, translation has indeed played a major role, positively. 
Think of the translation of Aristotelian works into Arabic and the subsequent translations of Averroës into Latin just as two cases in point. We should either move forward, all of us, all races, all dogmas, all nations and all faiths, or, otherwise, waste all our energies, powers, efforts and times, fearing each other, avoiding the philosophy and culture of each other, conflicting with each other and, ultimately, putting an end to the movie or drama series of human life on this planet with hatred, violence and blood. The choice is yours, or rather: ours.

It remains to be said that this paper does not claim to give any kind of decisive answers. In fact, it is more concerned with posing questions, reflecting on possible causes of certain subtitles translation problems and, eventually, the researcher only aspires to have helped pave the way before further research on the topic in question as well as related issues.

\section{References}

Anthony, P. (2014). Exploring Translation Theories. USA: Routledge.

Armstrong, S., Caffrey, C., \& Flanagan, M. (2006). Translating DVD subtitles from English-German and English-Japanese using Example-Based Machine Translation. EU-High-Level Scientific Conference Series MuTra 2006-Audiovisual Translation Scenarios: Conference Proceedings.

Awung, F. (2013). Agency in translating Une Vie de Boy into English: Exploring translator identity and translation strategies. Stellenbosch Papers in Linguistics Plus, 43, 1-14.

Bassnett, S., \& Lefevere, A. (1990). Translation, History, and Culture. London: Pinter Publishers.

Chen, S. J. (2015). Linguistic Dimensions of Subtitling. Perspectives from Taiwan. Meta: Translators' Journal, 49(1), 115-124.

Livanios, D. (2014). In the beginning was the word: Orthodoxy and Bible translation into Modern Greek (16th-19th centuries). Mediterranean Chronicle, 4(4).

Lv, L. G., Zhu, H. Y., \& Ning, P. Y. (2014). Subtitle Translation of Foreign Movies and TV Series under Skopos $\begin{array}{lll}\text { Theory. } & \text { JLTR, } & \text { 901-905. }\end{array}$ http://ojs.academypublisher.com/index.php/jltr/article/view/jltr0504901905/9604

Martin, V., Rico, S., Christian, H., \& Frida, T. (2010). Machine Translation of TV Subtitles for Large Scale Production. In V. Zhechev (Ed.), Proceedings of the Second Joint EM+/CNGL Workshop "Bringing MT to the User: Research on Integrating MT in the Translation Industry” (JEC '10) (pp. 53-62).

Mei, Z. F. (2015). On the Translation Strategies of English Film Title from the Perspective of Skopos Theory. $\begin{array}{llll}J L T R, & l(1), & 66-68 . & \text { Retrieved }\end{array}$ http://ojs.academypublisher.com/index.php/jltr/article/viewFile/01016668/1509

Munday, J. (2001). Introducing Translation Studies: Theories and Applications. London and New York: Routledge.

Zhang, Y., \& Liu, J. Y. (2009). Subtitle Translation Strategies as a Reflection of Technical Limitations: a Case Study of Ang Lee's Films. Asian Social Science, 5(1).

\section{Copyrights}

Copyright for this article is retained by the author(s), with first publication rights granted to the journal.

This is an open-access article distributed under the terms and conditions of the Creative Commons Attribution license (http://creativecommons.org/licenses/by/3.0/). 